\title{
Cost-effective Solar Concentrators based on Red Fluorescent
}

\section{Zn(II)-Salicylaldiminato Complex}

Pierpaolo Minei, ${ }^{a}$ Elisabetta Fanizza, ${ }^{\text {bc }}$ Antonio M. Rodríguez, ${ }^{\mathrm{d}}$ Ana Belén Muñoz-García, ${ }^{\mathrm{d}}$ Paola Cimino, ${ }^{\mathrm{e}}$ Michele Pavone, ${ }^{*, \mathrm{~d}}$ Andrea Pucci $*$,f,g

(a) Scuola Normale Superiore, Piazza dei Cavalieri 7, I-56126 Pisa, Italy

(b) Dipartimento di Chimica, Università degli Studi di Bari, Via Orabona 4, 70126 Bari, Italy

(c) CNR-Istituto per i Processi Chimico Fisici, UOS Bari, Via Orabona 4, 70126 Bari, Italy

(d) Dipartimento di Scienze Chimiche, Università di Napoli Federico II, Complesso Universitario Monte Sant'Angelo Via Cintia 21, 80126 Napoli, Italy

(e) Dipartimento di Scienze Farmaceutiche Università degli Studi di Salerno, Via Ponte don Melillo, I-84084 Fisciano (Salerno) Italy

(f) Dipartimento di Chimica e Chimica Industriale, Università di Pisa, Via Moruzzi 13, 56124 Pisa, Italy

(g) INSTM, UdR Pisa, Via Moruzzi 13, 56124 Pisa, Italy

* Corresponding authors: A. P. andrea.pucci@unipi.it; M.P. michele.pavone@unina.it

\begin{abstract}
Sunlight concentration is a promising path to cost-effective photovoltaic (PV) technologies. Compared to standard concentrators based on geometrical optics, luminescent solar concentrators (LSCs) appear as a viable and convenient alternative being sunlight concentration to PV occurs with diffuse light and no needs of sun tracking or cooling apparatuses. In this work, we report on the optical efficiencies of luminescent solar concentrators (LSCs) based on poly(methyl methacrylate) (PMMA) thin films doped with a red-emitting zinc (II) complex of the D-A-D type ligand N,N'bis(2-hydroxy-1-naphthylidene)-diaminomaleonitrile $(Z n L)$. $Z n L$ is attractive for use in LSC thanks to its easy and cheap synthesis. $Z n L$ in PMMA showed an emission band peaked at $624 \mathrm{~nm}$, a Stokes shift of $34 \mathrm{~nm}$ and an average QY of 23\%, data comparable to those recorded in solution and efficiently predicted by DFT calculations. Study of the ZnL/PMMA LSC yields optical efficiencies of 7\%, that is comparable to those based on the near unity QY fluorophores such as Lumogen Red. These performances were attributed to the higher emission red-shift and larger Stokes shift of $Z n L$ that prevent loss of efficiencies due to self-absorption and possibly circumvent its lower QY.
\end{abstract}

\section{Keywords}

Red-emitting metal-organic complex • PMMA thin films • Electronic structure • Quantum chemical calculations $\bullet$ Luminescent solar concentrators 


\section{Introduction}

Since the dawning of solar power production, concentration of solar radiation has been proposed as a solution to decrease the price of photovoltaic energy. Solar concentration is achieved by collecting the sun radiation incident on a large surface and redirecting it on a smaller area, thus allowing to reduce the amount of photoactive materials, which has the largest impact on the final costs. ${ }^{1-3}$ There are mainly two kinds of solar concentrators, one is based on geometrical optics (passive concentrators) $)^{4}$ and another group is based on luminescent components (active solar concentrators). ${ }^{3}$, ${ }^{5}$ Solar power fields with passive concentrators made of parabolic mirrors and Fresnel lenses are already a reality since they take a large area of sunlight and direct it toward a specific spot by bending the rays of light and focusing them. ${ }^{6}$ It has the advantages of working for all wavelengths, since it depends on reflection rather than refraction, and of not requiring any extreme materials properties. ${ }^{7}$ While capable of achieving extremely high concentrations (several hundred suns), ${ }^{8}$ the current technology suffers of some practical limitations: size limit (it is very long compared to its diameter), dependence on sunlight incidence angle, needs of large and heavy sun tracking systems and cooling apparatuses ${ }^{9,10}$ These features have hindered the deployment of such technology in urban environments and, in the past decades, active luminescent solar concentrators (LSCs) have been proposed as a viable and convenient alternative to classic geometric concentrators. ${ }^{11}$ LSCs show several advantages: the ability to work with diffuse light, light weight, reduced costs, and transparency are few examples. ${ }^{12,} 13$ These last features make LSCs very well suited to be implemented in modern building architectures, which make use of plenty of coloured windows and panels. ${ }^{14}$ Moreover, the use of commodity plastics and well consolidated and economic industrial processes for the preparation of LSCs offer encouraging means to include solar energy to the built environment.

The standard LSC device consists in a slab of transparent material (usually glass or polymer) doped with fluorescent dyes that absorb in the solar spectrum. ${ }^{14-16}$ The refractive index of the host is higher than the outer environment: total internal reflections allow to trap inside the LSC a large fraction of the dye emitted photons, which are thus collected and concentrated at the device edges where a PV module can be attached. In the recent years, the research on PV devices based on LSC technology has been focusing on obtaining high power conversion efficiencies. ${ }^{13,17-26}$ Still, prototype single-dye LSC coupled to commercial Si cells achieved so far efficiencies no higher than $3 \%$. ${ }^{14}$ Such low performances are mostly due to the many losses of such devices, due to both the physics of the phenomena and a not-yet-optimized fluorescent system. ${ }^{27}$

A simple approach for higher concentrations is to enhance the spectral window of absorption of the LSC, therefore increasing the number of available photons. To this end, multiple dye systems have 
long been proposed to cope for the narrow absorption characteristic of organic dyes as well as new design solutions. ${ }^{12,22,28}$ Noble metals nanoparticles ${ }^{29}$ and Quantum Dots have also been investigated for their broad absorption features although compatibility issues between the fluorophore and commercial matrices seldom arise. ${ }^{18,30-32}$ Conversely, to best of our knowledge, only a few examples concern the use of metal complexes. Tris(8hydroxyquinolinolate)aluminum(III) (Alq3) and platinum tetraphenyltetrabenzoporphyrin $[\mathrm{Pt}(\mathrm{TPBP})]$ have been effectively employed as robust photoemitters in stacked high-efficiency LSCs. $^{22}$ Indeed, the organic metal-chelate complexes usually offer additional convenient features such as high thermal and optical stability, ${ }^{33,34}$ wide absorption range and luminescent properties. For these reasons, a promising red-emitting zinc (II) complex of the donor-acceptor-donor (D-A-D) type ligand N,N'-bis(2-hydroxy-1-naphthylidene)-diaminomaleonitrile $\left(\mathrm{H}_{2} \mathrm{~L}\right)$ was investigated (Figure 1). One of the main appeals of this class of inorganic complexes is that molecular engineering permits systematically altering spectroscopic and chemical properties. This chemical flexibility allows for the design of systems that respond to specific environmental variables. $\mathrm{Zn}$ (II) complexes bearing salicylaldiminato ligands have been particularly employed as emitters in organic optoelectronics, $^{33,35,36}$ and also exhibit a broad range of eco-friendly catalytic ${ }^{37}$ and biological activities. ${ }^{38,39}$ Notably, considering the easy and cheap synthetic route, $Z n L$ might represent the first example of a cost-effective red-emitting Shiff base complex alternative to traditional organic fluorophores in LSCs applications. For example, Lumogen Red, i.e the state-of-art of fluorophores for LSCs, is nowadays quoted at about $7,500 € / \mathrm{kg}$ by BASF, that is an issue that definitely affects the final cost of these devices, thus limiting their worldwide distribution.

Here, a joint experimental and computational study of $Z n L$ spectroscopic properties in different solutions was reported. By analyzing electronic structure features and optical properties the nature of absorbing and emitting states was dissected, identifying the role of $\mathrm{Zn}$ and the importance of $\mathrm{Zn}$ solvent interactions in determining the observed spectra. Motivated by these results, the optical features of $Z n L$ were investigated when dispersed in transparent amorphous poly-methylmethacrylate (PMMA) thin films, aiming at the realization of a new LSC device. While bulk-plate configurations assure a larger number of fluorophores embedded without generating significant efficiency loss due to concentration, the thin film procedure offers numerous advantages in the experimental process ${ }^{40,41}$ such as limited use of materials, and easy and fast setup: required conditions for the large-scale preparation of LSC samples. 


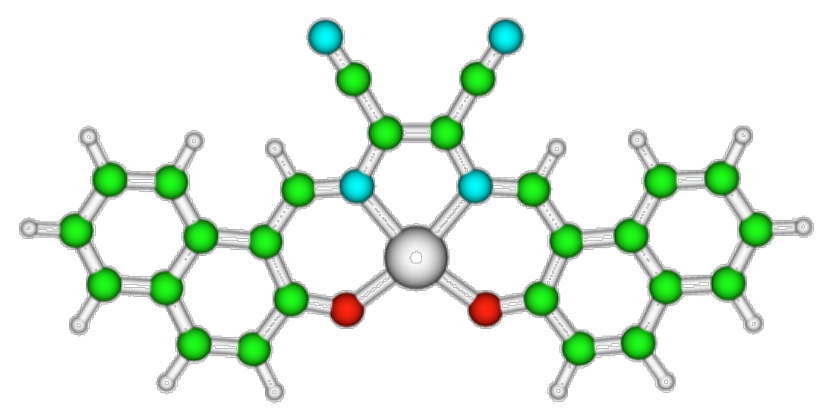

Figure 1. Structure of Zinc N,N'-bis(2-hydroxy-1-naphthylidene)-diaminomaleonitrile ( $Z n L)$. Atoms are represented by spheres of different colours: $\mathrm{Zn}$ grey, $\mathrm{C}$ green, $\mathrm{O}$ red, $\mathrm{N}$ cyan, and $\mathrm{H}$ white.

\section{Experimental Section}

\section{Materials}

Poly(methyl methacrylate) (PMMA, Aldrich, $\mathrm{Mw}=350,000 \mathrm{~g} / \mathrm{mol}$, acid number $<1 \mathrm{mg} \mathrm{KOH} / \mathrm{g}$ ), was used as received. N,N'-bis(2-hydroxy-1-naphthylidene)-diaminomaleonitrile $\left(\mathrm{H}_{2} \mathrm{~L}\right)$ and its neutral $\mathrm{Zn}$ (II) complex were prepared and characterized following a literature procedure. ${ }^{42}$ Unless otherwise stated, commercially available materials were used as received.

Synthesis of $\mathrm{H}_{2} \mathrm{~L}: 1 \mathrm{~g}(5.8 \mathrm{mmol})$ of 2-hydroxy-1-naphthaldehyde, $0.31 \mathrm{~g}$ (0.29 mmol) diaminomaleonitrile were mixed in a mixture of DMF $(40 \mathrm{~mL})$ and acetic acid $(10 \mathrm{~mL})$ and stirred at room temperature. After addition of 1 drop of concentrated sulphuric acid, the mixture was stirred at $80^{\circ} \mathrm{C}$ for $8 \mathrm{~h}$. The deep green precipitate was filtered, washed with DMF and ethanol, and air-dried to yield $0.5 \mathrm{~g}(41.3 \%)$ of product. m.p. $>300{ }^{\circ} \mathrm{C}$. Anal. Calc. for $\mathrm{C}_{26} \mathrm{H}_{16} \mathrm{~N}_{4} \mathrm{O}_{2}(\%)$ : C, 74.99; H, 3.87; N, 13.45. Found: C, 75.15; H, 3.92; N, 13.38. FT-IR (KBr) $\left(\mathrm{cm}^{-1}\right): 3421(\mathrm{OH}), 2218$ $(\mathrm{C} \equiv \mathrm{N}) 1618(\mathrm{C}=\mathrm{N}) .{ }^{1} \mathrm{H}$ NMR $\left(300 \mathrm{MHz}, \mathrm{CDCl}_{3}\right): \delta=7.21$ (d, 2H; ArH), $7.34(\mathrm{dd}, 2 \mathrm{H} ; \mathrm{ArH}), 7.50$ (dd, 2H, ArH), 7.80 (d, 2H, ArH), 7.84 (d, 2H, ArH), 8.00 (d, 2H, ArH), 9.70 (s, 2H; CHN), 12.93 (s, 2H; OH).

Synthesis of ZnL: a mixture of $1 \mathrm{~g}(5.8 \mathrm{mmol})$ of 2-hydroxy-1-naphthaldehyde, $0.31 \mathrm{~g}(0.29 \mathrm{mmol})$ diaminomaleonitrile and $0.64 \mathrm{~g}(0.29 \mathrm{mmol})$ of $\mathrm{Zn}\left(\mathrm{CH}_{3} \mathrm{COO}\right)_{2} \cdot 2 \mathrm{H}_{2} \mathrm{O}$ were mixed in DMF $(100 \mathrm{~mL})$ and stirred at room temperature for $1 \mathrm{~h}$. The resulting mixture was filtered and cooled in a freezer, which provided the appearance of black crystals $\left(60 \%\right.$ yield). Anal. Calc. for $\mathrm{C}_{32} \mathrm{H}_{28} \mathrm{~N}_{6} \mathrm{O}_{4} \mathrm{Zn}$ ([ZnL]2DMF)(\%): C, 61.40; H, 4.51; N, 13.42. Found: C, 61.62; H, 4.40; N, 13.54. FT FT-IR $(\mathrm{KBr})\left(\mathrm{cm}^{-1}\right): 2213(\mathrm{C} \equiv \mathrm{N}) 1615(\mathrm{C}=\mathrm{N}) .{ }^{1} \mathrm{H}$ NMR $\left(300 \mathrm{MHz}, \mathrm{CDCl}_{3}\right): \delta=6.73(\mathrm{~d}, 2 \mathrm{H} ; \mathrm{ArH}), 7.00$ 
(m, 2H; ArH), $7.11(\mathrm{~m}, 2 \mathrm{H}, \operatorname{ArH}), 7.36$ (d, 2H, ArH), 7.51 (d, 2H, ArH), 7.60 (d, 2H, ArH), $9.31(\mathrm{~s}$, $2 \mathrm{H} ; \mathrm{CHN})$.

\section{Preparation of ZnL/PMMA films}

Different $Z n L /$ PMMA thin films were prepared by drop casting, i.e. pouring $0.8 \mathrm{~mL}$ chloroform solution containing $30 \mathrm{mg}$ of the polymer and the proper amount of dye to obtain concentrations in the range $0.05-2.2 \mathrm{wt} . \%$ on $35 \times 50 \mathrm{~mm}$ area over a glass surface. The glass slides were cleaned with chloroform and immerged in $6 \mathrm{M} \mathrm{HCl}$ for at least $12 \mathrm{~h}$, then they were rinsed with water, acetone and isopropanol and dried for $8 \mathrm{~h}$ at $120{ }^{\circ} \mathrm{C}$. Solvent evaporation was performed on a warm hot plate (about $30{ }^{\circ} \mathrm{C}$ ) and in a closed environment. The film thickness was measured by a Starrett micrometer to be $25 \pm 5 \mu \mathrm{m}$. The PMMA films were easily removed with a spatula after immersion in water so that they can be stored for successive measurements and comparison by attaching them on 50x50x3 mm optically pure glass substrate (Edmund Optics Ltd BOROFLOAT window 50x50 TS) with a high-purity silicone oil with a refractive index comparable to PMMA and glass (i.e., poly(methylphenyl siloxane), 710 fluid, Aldrich, refractive index $n=1.5365$ ). Absorption and emission properties of such devices showed negligible differences with the freshly prepared ones.

\section{Characterizations}

Melting points were recorded on a hot-stage microscope (Reichert Thermovar). FT-IR spectra were recorded with the help of a Perkin Elmer Spectrum One spectrometer in KBr dispersions. NMR spectra were recorded at room temperature at $300 \mathrm{MHz}\left({ }^{1} \mathrm{H}\right)$ and were referred to TMS or to the residual protons of deuterated solvents. Absorption spectra were recorded at room temperature on a Perkin-Elmer Lambda 650 spectrometer. Fluorescence spectra were measured at room temperature on a Horiba Jobin-Yvon Fluorolog ${ }^{\circledR}-3$ spectrofluorometer equipped with a $450 \mathrm{~W}$ xenon arc lamp, double-grating excitation and single-grating emission monochromators. The emission quantum yields of the solid samples were obtained by means of a $152 \mathrm{~mm}$ diameter "Quanta-phi" integrating sphere coated with Spectralon ${ }^{\circledR}$ and mounted in the optical path of the spectrofluorimeter, using as an excitation source a $450 \mathrm{~W}$ Xenon lamp coupled with a double-grating monochromator for selecting wavelengths.

\section{Photocurrent measurements ${ }^{43}$}

A proper apparatus was build and composed by a plywood wooden box $15 \times 15 \times 30 \mathrm{~cm}$ with walls $1.5 \mathrm{~cm}$ thick. A removable cover hosting a housing for a solar lamp is present at the top. During the measurement a solar lamp TRUE-LIGHT® ESl E27 20W was used. Two 50x3 mm slits were 
carved out at $5 \mathrm{~cm}$ from the bottom of the box to exactly fit the LSC systems (dimensions 40x50x3 $\mathrm{mm}$ ) so that the minimum amount of light would come out during the measurement conditions. On the outer side of the slit, a set of three 1x1 cm photodiodes (THORLABS FDS1010 Si photodiode, with an active area of $9.7 \times 9.7 \mathrm{~mm}$ and high responsivity (A/W) in the spectral range of 400-1100 $\mathrm{nm}$ (Figure S1)) connected in parallel fashion was placed and coupled to a multimeter (KEITHLEY Mod. 2700) for photocurrent measuring.

Efficiency measurement using a PV-cell ${ }^{43}$

A different set of LSC samples was prepared to measure the concentration efficiency attaching a SiPV cell (IXYS SLMD121H08L mono solar cell 86x14 mm, with a solar cell efficiency of 14\% and a fill factor $>70 \%$ ) to one edge of the sample. This set of samples was made covering the $40 \times 50$ area of the previously introduced optically pure glass slabs with a $25 \pm 5 \mu \mathrm{m} Z n L /$ PMMA thick film. One edge of the LSC was connected to a Si-based PV cell masked to cover just the LSC edge (50x3 $\mathrm{mm}$ ) using silicone grease while the remaining edges were covered with an aluminum tape. These devices where then placed over a white poly(ethylene terephthalate) scattering sheet (Microcellular® MCPET reflective sheet, ERGA TAPES Srl) and placed about $20 \mathrm{~cm}$ under a solar lamp (TRUELIGHT® ESL E27 20W, with a correlated colour temperature of $5500 \mathrm{~K}$ ). The efficiency is reported as $\eta_{\text {opt }}$, which is the ratio between the short circuit current of the PV cell attached the LSC edges under illumination of a light source $\left(\mathrm{I}_{\mathrm{LSC}}\right)$ and the short circuit current of the bare cell put perpendicular to the light source $\left(\mathrm{I}_{\mathrm{SC}}\right)$.

\section{Computational details}

$Z n L$ molecular structure, vertical excitation and emission properties have been characterized by means of quantum chemical calculations based on density functional theory (DFT) and timedependent DFT (TD-DFT) approaches. ${ }^{44-47}$ Several tests were performed for choosing the best accurate level of theory at the most feasible computational costs. After comparing different density functional models, the most commonly employed B3LYP hybrid DFT functional was chosen, ${ }^{48,49}$ using higher content of non-local exact exchange or a long-range corrected hybrid-DFT approach did not provide significant improvements over B3LYP (see Supporting Information, Table S1). Calculations address the prediction of intra-ligand electronic transitions. For this processes, the choice of the basis set for the ligand atoms is crucial. Double- and triple- $\zeta$ basis set from the Pople's and Dunning's series was tested, plus the addition of diffuse and polarization functions. After convergence tests (see SI, Table S2), we adopted the $6-311++\mathrm{G}(\mathrm{d}, \mathrm{p}){ }^{50,51}$ basis set for $\mathrm{C}, \mathrm{N}, \mathrm{O}$ and $\mathrm{H}$ atoms. For the $\mathrm{Zn}$ atom, the LANL2TZ+ effective core potential (ECP) and basis set were used. ${ }^{52}$, 
${ }^{53}$ Testing other different ECP-basis set combinations for $\mathrm{Zn}$ did not affect the predicted $\mathrm{ZnL}$ electronic structure. In structural optimizations, molecular frequencies and electronic transition calculations, the bulk solvent effects have been taken into account by means of the well-known Polarizable Continuum Model (PCM) implicit solvation scheme. ${ }^{54-56}$ In particular, the $Z n L$ adsorption and emission properties in solution have been computed according to the state-specific PCM approach. ${ }^{57,58}$ All the calculations were performed with the Gaussian 09 suite of programs for quantum chemistry. ${ }^{59}$

\section{Results and Discussion}

Optical characterization of the ZnL in solution

$Z n L$ was prepared according to Liuzzo and Di Bella: ${ }^{42,60}$ the FTIR spectra showed the stretching of imines groups $\left(1615 \mathrm{~cm}^{-1}\right)$ and nitrile groups $\left(2213 \mathrm{~cm}^{-1}\right)$ of $\mathrm{ZnL}$, whereas ${ }^{1} \mathrm{H}$ NMR and elemental analysis confirmed $\mathrm{ZnL}$ composition.

The UV-vis absorption spectra of dilute dioxane (DOX) and Tetrahydrofuran (THF) solutions of $Z n L$ are shown in Figure 2. The absorption spectra indicate that the electronic transition should be attributed to intramolecular charge transfer (ICT), due to the conjugated nature of the Schiff base complex, as occurred in other salicylaldiminate systems containing the diaminomaleonitrile bridge. $^{60,61}$ The absorption maxima of $Z n L$ in dioxane (dielectric constant $=2.25$, Figure $2 \mathrm{a}$ ) and THF (dielectric constant $=7.58$, Figure $2 \mathrm{~b}$ ) are located at $589 \mathrm{~nm}$ and $595 \mathrm{~nm}$, respectively. The emission spectra $\left(\lambda_{\text {exc. }}=450 \mathrm{~nm}\right)$ of $Z n L$ in dioxane and THF solutions exhibit intense unstructured bands with maxima at $621 \mathrm{~nm}($ Stokes shift $=32 \mathrm{~nm})$ and $630 \mathrm{~nm}$ (Stokes shift $=35 \mathrm{~nm}$ ), respectively.

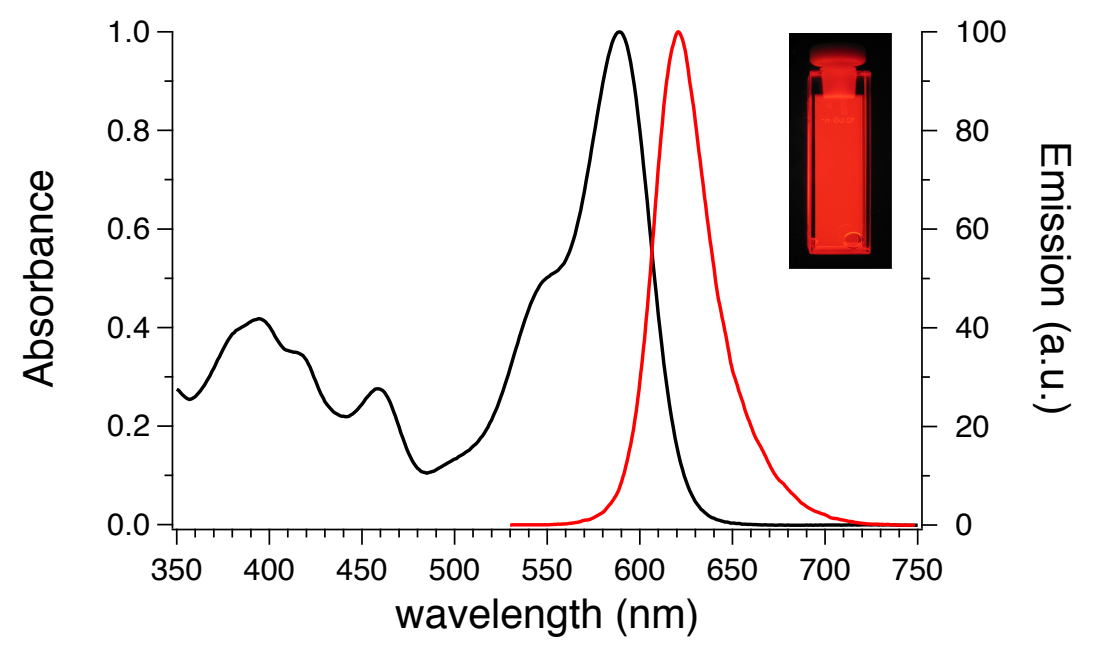

(a) 


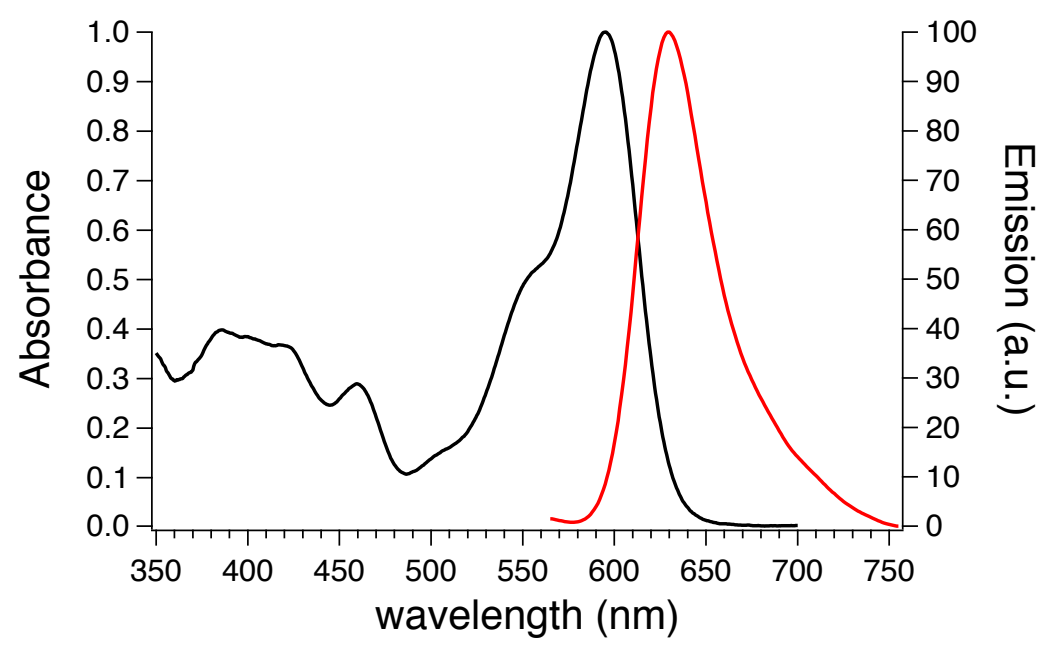

(b)

Figure 2. Normalised absorption and emission $\left(\lambda_{\text {exc. }}=450 \mathrm{~nm}\right)$ spectra of $Z n L$ in (a) dioxane and (b) THF solutions $\left(5 \cdot 10^{-6} \mathrm{~mol} / \mathrm{L}\right)$. The red emission of the $Z n L$ dioxane solution (inset Figure 1a) was taken by exciting with a Dark Reader 46B transilluminator (Multiple blue LEDs, $\sim 450 \mathrm{~nm}$ ).

The electronic features behind these $Z n L$ optical spectra have been investigated with state-of-the-art Density Functional Theory (DFT) and Time Dependent-DFT (TD-DFT) calculations. Structural optimizations of ground- and first-excited electronic states have been performed with the polarizable continuum model (PCM) for DOX and THF solutions. Also, a discrete-continuum cluster model approach was applied with explicit solvent molecules and PCM to account for both short-range and long-range solute-solvent interactions: ${ }^{62,63}$ in these cases two solvent molecules have been placed in perpendicular direction to the $Z n L$ plane, respectively above and below the planar dye, with oxygen atoms pointing toward the $\mathrm{Zn}$ cation. The computed structural data are reported in Supporting Material (Table S3 and S4). The predicted adsorption and emission vertical transition energies are reported in Figure 3 together with the $Z n L$ molecular orbital energy levels in Dioxane and Tetrahydrofuran, and the isodensity surface plots for the molecular orbitals that are interested in these transitions (HOMO-LUMO). 

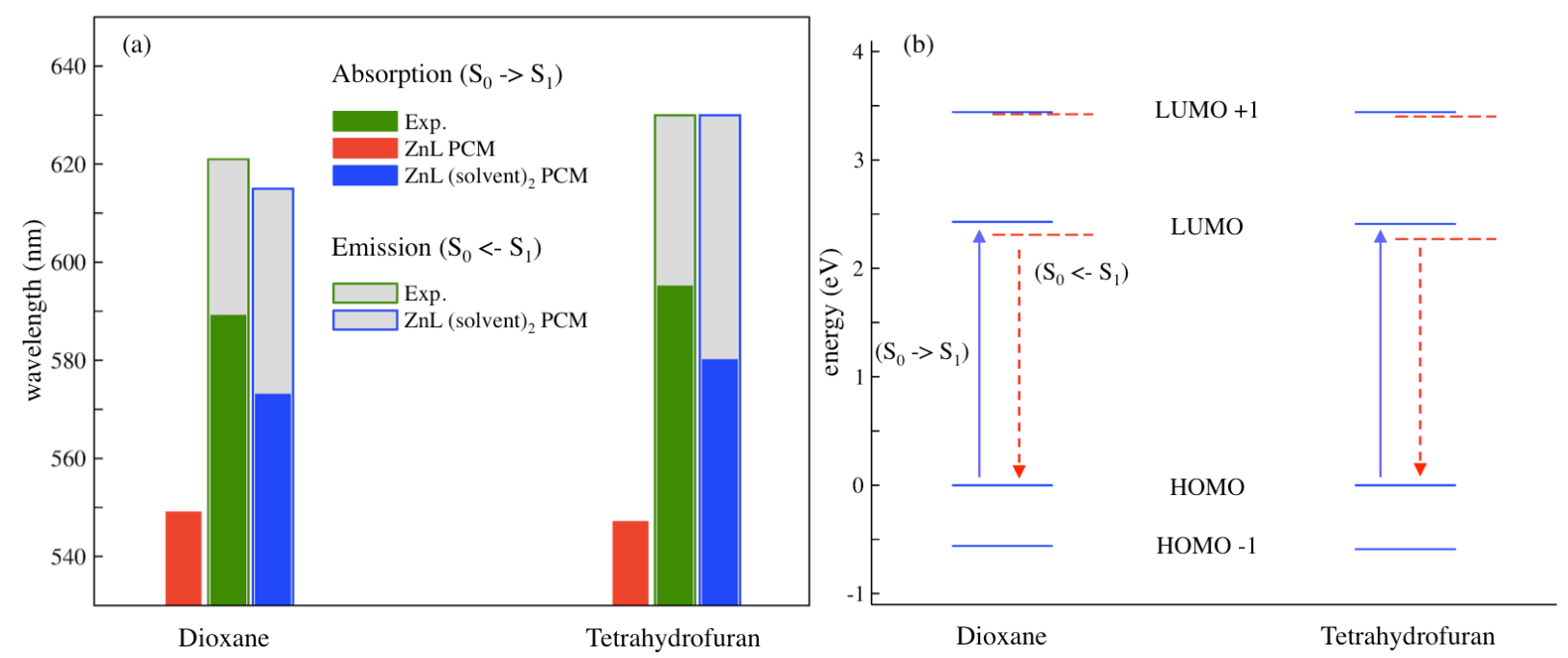

(c)
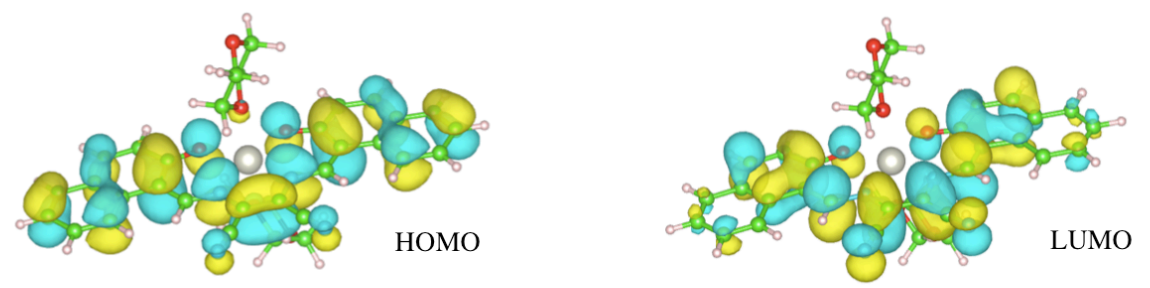

Figure 3. (a) TD-DFT computed vertical excitation and emission energies computed on ground $\left(\mathrm{S}_{0}\right)$ and excited state $\left(\mathrm{S}_{1}\right)$ minima, respectively, in dioxane and THF solutions. Implicit, PCM, and discrete-continuum, (solvent)2-PCM, solvation model are compared on absorption energies. Experimental values are from Figure 2; the grey area represents the Stokes shift. (b) Molecular orbital (MO) energy levels for $\mathrm{ZnL}$ (Dioxane) $)_{2}-\mathrm{PCM}$ and $\mathrm{ZnL}$ (Tetrahydrofuran) $)_{2}-\mathrm{PCM}$ : blue solid lines represent the MOs at the ground state minimum, while the dashed red lines represent the MO levels at the S1 TD-DFT optimized structure; the vertical transitions of interest in absorption (solid blue arrow) and emission (dashed red arrow) involve only HOMO and LUMO orbitals. (c) Isodensity surface plots of HOMO and LUMO molecular orbitals for the ZnL(Dioxane) $)_{2}$-PCM system (positive and negative values are depicted in yellow and cyan, respectively, with a contour threshold value of 0.02 ).

From a computational perspective, the implicit solvation scheme was found insufficient to predict the solvent effects: the vertical absorption values are far off the experimental ones for both DOX and THF. Moreover, the PCM is not even able to distinguish between the two solvents. When

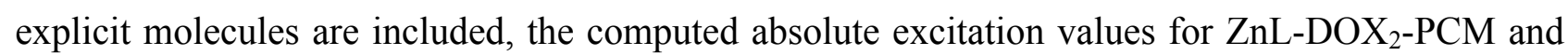
ZnL-THF $2-\mathrm{PCM}$ still present an error when compared to experiments $(\sim 2 \%)$, but it falls within the expected accuracy of our approach. Moreover, the discrete-continuum predictions are much closer than PCM ones to the reference values and, noteworthy, they have been also able to describe the red shift of $Z n L$ absorption in THF with respect to DOX solution. The $Z n L-\mathrm{DOX}_{2}-\mathrm{PCM}$ and $Z n L-\mathrm{THF}_{2}-$ PCM model systems were also employed to predict the excited-state minimum energy structures and the corresponding vertical emission energies. The predicted emission energies are in better 
agreement with experiments than the adsorption values. The electronic excitation process has an intra-molecular charge-transfer (CT) nature. Figure 3c shows the HOMO and LUMO molecular orbitals that are involved in the predicted and observed transitions. The HOMO is well localized across the aromatic moieties, while the LUMO has an important localization on the CN moieties. These qualitative features are the same in both DOX and THF solutions. This behaviour is in line with the fluorescence of zinc(II) complexes, which are determined only by the $\pi-\pi *$ transition of the organic ligand because the $\mathrm{d}$ shell of the central ion is completely filled. ${ }^{64}$ Moreover, our MO analysis also explains why the absorption and emission maxima of $Z n L$ are red-shifted in THF: because of its higher dielectric constant than dioxane, THF provides a small but sensible stabilization of the CT excited state.

Despite the slight overestimation of the Stokes shift, the proposed discrete-continuum model provided overall a reliable qualitative estimate of electron absorption and emission transitions. Therefore, the same protocol to model the electronic structure of $Z n L$ was applied when embedded into the PMMA thin film, our target LSC host matrix. PMMA is an amorphous polymer matrix with a dielectric constant of 2.6-2.8, so for modelling the polymer matrix the PCM model was safely employed (setting the dielectric constant to the average value of 2.7). Moreover, the presence of exposed oxygen atoms in the PMMA lateral residues can lead to direct coordination of these oxygen moieties to the $\mathrm{Zn}$ ion in $\mathrm{ZnL}$. Thus, for modelling the $Z n L / P M M A$ system a discretecontinuum approach was used, as done with DOX and THF. Table S5 in Supporting Material lists the main structural and electronic features of the ground and excited state minima. The TD-DFT predicted absorption and emission energies $\left(\lambda_{\mathrm{abs}}=577 \mathrm{~nm} ; \lambda_{\mathrm{ems}}=619 \mathrm{~nm}\right)$ are very close to the DOX ones, with a similarly convenient Stokes shift $(\sim 42 \mathrm{~nm})$. Such behaviour was expected because the chemical nature of PMMA lateral residues and PMMA bulk dielectric constant are very similar to those of DOX solution. Motivated by these positive $a b$ initio results on structural properties and electronic transition energies, the experimental characterization of $\mathrm{ZnL} / \mathrm{PMMA}$ films for LSC applications was therefore performed.

\section{Optical characterization of the ZnL/PMMA films}

Owing to the aforementioned opto-electronic properties, $Z n L$ was also investigated when dispersed in the transparent and totally amorphous polymer matrix of PMMA. PMMA was selected as polymer matrix due to its completely amorphous state, which confers the material optical transparency and good mechanical properties. PMMA is also cheap and commercially available, characteristics that make this polymer a perfect candidate for large scale LSC applications. ${ }^{65,66}$ 
The optical characteristics of $Z n L$ in the PMMA matrix are shown in figure 4 with maximum absorption and emission bands found at $590 \mathrm{~nm}$ and $624 \mathrm{~nm}$, respectively, with a Stokes shift of 34 nm. ZnL absorbs light down to $500 \mathrm{~nm}$ as well, thanks to a second structure-less band centred at $450 \mathrm{~nm}$. Both emission maximum and Stokes shift in PMMA are comparable to those recorded in dioxane solutions due to almost identical dielectric constants.

The absolute fluorescent quantum yield (QY) of $Z n L$ in PMMA reached an average value of $23 \%$, which was maintained even at the highest concentration investigated (i.e. $22.5 \%$ for 1 wt.\% $Z n L / P M M A$ film). This value is lower than that of DOX solution (39\%) but still comparable to that recorded for fluorophores dispersions at such a long wavelength emission $(\sim 630 \mathrm{~nm}) .{ }^{67}$

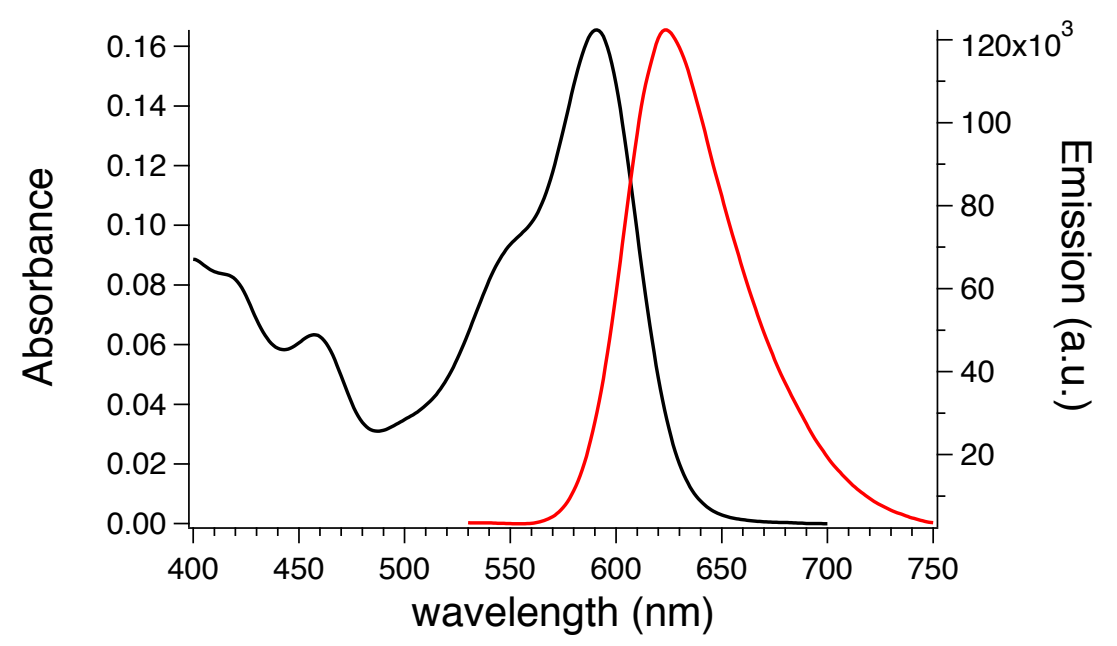

Figure 4. Absorption and emission spectra $\left(\lambda_{\mathrm{exc}}=450 \mathrm{~nm}\right)$ of a 0.3 wt. $\% \mathrm{ZnL} / \mathrm{PMMA}$ film with a thickness of $25 \pm 5 \mu \mathrm{m}$

Measurement of the LSC efficiencies are usually performed by attaching PV modules to the concentrating system and irradiating it with a light source that emulates the solar conditions. ${ }^{25,26,40}$ While this approach is effective to evaluate the ultimate LSC performances, it has created a lot of confusion in the literature data, ${ }^{14}$ since many research groups make use of different and not always directly comparable conditions and experimental setups on their pursue to the best performing LSC system. More than that, sometimes LSCs are evaluated with parameters referred to other solar generating systems like photon-per-electron efficiencies or fill factors which are meaningless in this specific case since the LSC itself is not an energy generating device but achieves light concentration only. ${ }^{14}$ In order to assess the performances as LSC, an optically pure 50x50x3 mm glass was coated with $Z n L /$ PMMA films with a thickness of $25 \pm 5 \mathrm{~mm}$. Photocurrent measurements were accomplished with a home-built apparatus ${ }^{43}$ (see experimental part) by using a set of three $1 \times 1 \mathrm{~cm}$ photodiodes assembled in parallel fashion. Photodiodes are ideal for measuring light sources in 
LSC emission range by converting the optical power to an electrical current, allowing for a fast, precise and reproducible response even with different sets of samples. This approach was used to study the best working conditions for different dye/polymer LSC systems since the response curves of the photodiodes and the utilized PV module do not differ significantly.

The photocurrents measured for a set of samples based on ZnL/PMMA thin films are reported in Figure 5.

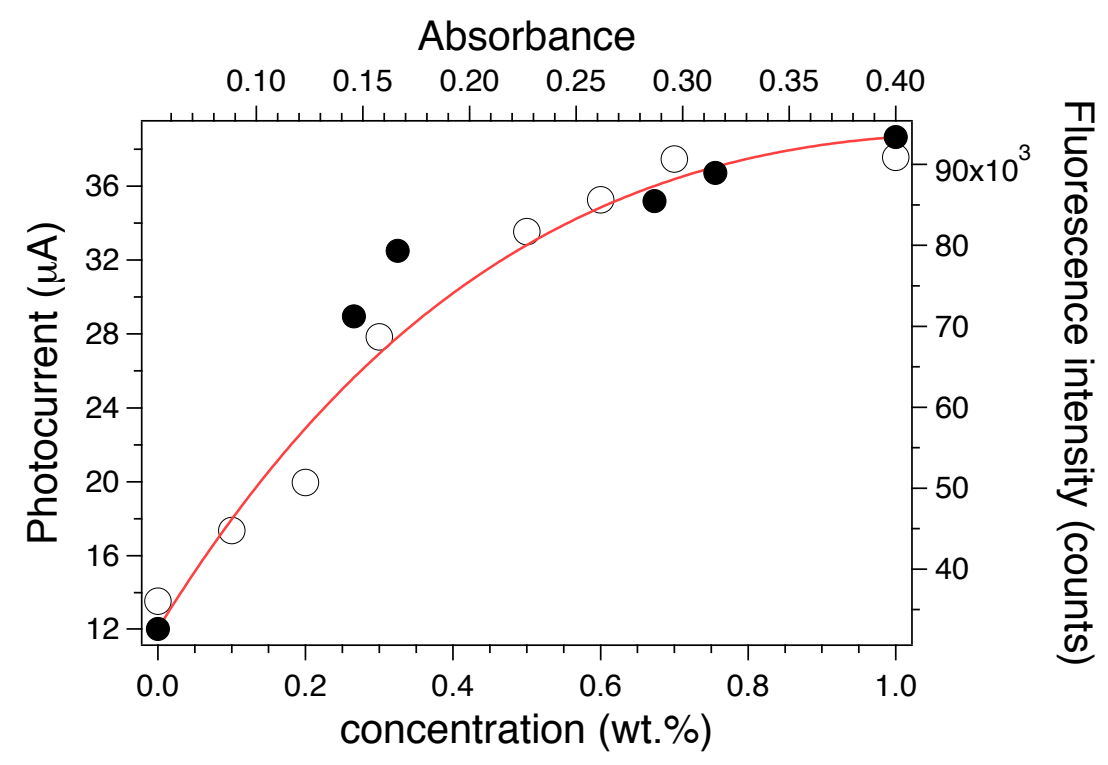

Figure 5. Fluorescence peak emission intensity vs. absorbance (black filled circles) of $Z n L / P M M A$ films of a thickness of $25 \pm 5 \mu \mathrm{m}$ with increasing dye concentration and photocurrent (open circles) measured for the same films at different dye content (wt.\%). Photocurrents were fitted with eq. 1 (red curve) with parameters listed in Table 1 (see below).

The data follow a peculiar trend, i.e. photocurrent increasing with $Z n L$ content and levelling off at the highest concentration investigated. This trend is quite in accordance with the plot of fluorescence emission intensity vs. absorbance, which is reported to reveal possible lost of the absorbed photons via non-radiative pathways. ${ }^{19}$ In detail, the emission intensity is found to increase linearly with the absorbance of $Z n L /$ PMMA up to $0.3 \mathrm{wt} . \%$ of fluorophore, indicating a negligible effect of dissipation phenomena. Conversely, when the concentration is further increased a deviation from linearity is observed, thus suggesting that dissipative phenomena occur.

Notably, the photocurrent behaviour fits quite well with eq. 1:

$$
\eta_{\text {opt }}=\varepsilon^{\prime} \cdot c \cdot e^{-\mu_{o p t} \cdot c}+D
$$


where $\eta_{\text {opt }}$ is the optical efficiency a term proportional to the current generated by photodiodes, $c$ is the concentration of the dye in wt.\%, and $\varepsilon^{\prime}$ and $\mu_{\text {opt }}$ are two empirical constants defined as:

$$
\begin{aligned}
& \varepsilon^{\prime} \propto h \cdot e^{-\bar{l}} \\
& \mu_{o p t} \propto \mu^{\prime \prime}(Q Y, p) \cdot \bar{l}
\end{aligned}
$$

where $h$ is the thickness of the thin film, $\bar{l}$ is the mean path length of the radiation in the optical system and $\mu^{\prime \prime}$ is a term depending on both QY and the probability of fluorescence re-absorption $(p)$, being greater at high $p$ and low QY. D is an empirical constant added since even an empty system of transparent material $(\mathrm{c}=0)$ is capable of trapping some light by means of surface and bulk defects due to scattering phenomena.

Eq. 1 was recently determined inspired by the work of Goezberger ${ }^{27}$ who proposed in 1977 an effective method to evaluate LSC efficiency. Both $\varepsilon^{\prime}$ and $\mu_{\text {opt }}$ must be considered as completely empirical since even the most accurate estimations require strong approximations. Nevertheless, the determination of how they affect the final $\eta_{\text {opt }}$ is straightforward for determining the LSC performances. Notably, $\varepsilon^{\prime}$ is a coefficient related to the absorption properties of the dye/polymer system, whereas $\mu_{\text {opt }}$ combines all the fluorescence quenching mechanisms due to the dye. An optimal dye/polymer system should therefore present a high $\varepsilon$ ' and a small $\mu_{\text {opt }}$ so that the maximum efficiency is shifted to higher concentrations and the curve steadily rises under the influence of the linear part (eq. 1). A complete and exhaustive determination of eq. 1 was recently reported in literature by our group. ${ }^{43}$

The fitting parameters, reported in Table 1, were compared to those recently gathered for PMMA films with the same thickness of $25 \pm 5 \mu \mathrm{m}$ but containing Lumogen Red F350 (LR), ${ }^{43}$ selected as reference as it is considered the state-of-the-art in dyes for LSC applications. ${ }^{14}$

Table 1. Fitting parameters of the photocurrent data measured for $Z n L / P M M A$ and LR/PMMA ${ }^{43}$ films. For both systems, the film thickness was $25 \pm 5 \mu \mathrm{m}$

\begin{tabular}{|c|c|c|c|}
\hline Entry & $\boldsymbol{\varepsilon}^{\prime}$ & $\boldsymbol{\mu}_{\text {opt }}$ & $\mathbf{D}$ \\
\hline ZnL/PMMA & 65 & 0.90 & 12 \\
\hline LR/PMMA & 140 & 0.45 & 20 \\
\hline
\end{tabular}

The fitting parameters of $Z n L / P M M A$ films were found to be different from those of LR/PMMA: lower values for $\varepsilon$ ' and slightly higher $\mu_{\text {opt }}$ were collected. On the contrary, D values resulted to be quite similar for all the dye/PMMA systems, thus suggesting that the contribution of nonfluorescent trapping is more or less the same for samples with the same thickness. The smaller $\varepsilon^{\prime}$ is 
a result of the lesser extinction coefficient of $Z n L$ compared to that of LR in PMMA, being $\varepsilon$ ' related to the light absorption properties of the system (Figure S2).

Nevertheless, $Z n L$ showed a $\mu_{\text {opt }}$ value comparable to that of LR, possibly due to the larger Stokes shift (34 $\mathrm{nm}$ for $Z n L$ against 23 for $\mathrm{LR}^{43}$ ) and a more red-shifted emission (624 $\mathrm{nm}$ for $Z n L$ against 609 for $\mathrm{LR}^{43}$ ), notwithstanding the lower QY compared to that of LR. ${ }^{43}$ Attempts to evaluate the effect of self-absorption on the LSC optical performances have been thoroughly reviewed in the literature. $^{40,68-71}$ Re-absorption of emitted photons by subsequent dye molecules via overlap of emission and absorption bands appears undoubtedly to be the limiting factor in respect to the efficiency of the concentrator. ${ }^{14,72}$ Moreover, a more red-shifted emission agrees better with the typical responsivity curve of photodiodes (Figure S1).

The $Z n L /$ PMMA films with the highest photocurrent, i.e. the those containing the 0.7 and $1 \mathrm{wt} . \%$ of $Z n L$, were analysed by using a Si-based PV cell attached to one edge of the concentrator, as described in the experimental section. The optical efficiency $\eta_{\text {opt }}$ (Table 2) was evaluated from the concentration factor $\mathrm{C}$, which is the ratio between the short circuit current measured in the case of the cell over the LSC edge ( $\mathrm{ILSC}_{\mathrm{LSC}}$ ) and short circuit current of the bare cell when perpendicular to the light source $\left(\mathrm{I}_{\mathrm{SC}}\right)$ (eq. 4):

$\eta_{\text {opt }}=\frac{\mathrm{I}_{\mathrm{LSC}}}{\mathrm{I}_{\mathrm{SC}} \cdot \mathrm{G}}($ eq. 4$)$

where $G$ is the geometrical factor (in our case, $G=13.3$ ), which is the ratio between the area exposed to the light source and the collecting area.

Table 2. Concentration factors $(C)$ and optical efficiencies $\left(\eta_{\text {opt }}\right)$ calculated for $Z n L /$ PMMA LSCs and compared to those of $Z n L /$ PMMA LSCs with similar geometrical factor ${ }^{19,43}$

\begin{tabular}{|c|c|c|c|}
\hline Entry & wt.\% & $\mathbf{C}$ & $\boldsymbol{\eta}_{\text {opt }}(\mathbf{\%})$ \\
\hline \multirow{2}{*}{$Z n L /$ PMMA } & 0.7 & 0.92 & 6.92 \\
\cline { 2 - 4 } & 1.0 & 0.90 & 6.76 \\
\hline LR/PMMA & $0.7-1.0$ & $0.94-1.06$ & $7.0-8.0$ \\
\hline
\end{tabular}

The calculated $\mathrm{C}$ and $\eta_{\mathrm{opt}}$ for the ZnL/PMMA system with the highest photocurrents were comparable to that gathered from LSC based on LR in the same range of fluorophore concentration and geometrical factor. This result suggests that despite the $23 \%$ of QY in PMMA, the red-emitting $\mathrm{ZnL}$ fluorophore yields LSC system with noteworthy optical efficiencies, possibly due to the larger Stokes shift and emission in the range of the highest quantum efficiency of the PV cell (600-770 nm, Figure S5). ${ }^{14,73}$

Preliminarily experiments aimed at the photostability determination of ZnL/PMMA thin films, revealed that the systems lost only 2-3\% of its emission during the first $15 \mathrm{~min}$ of continuous light 
irradiation at $450 \mathrm{~nm}$ (i.e., at $\lambda_{\text {exc.) }}$ with a $450 \mathrm{~W}$ Xe arc lamp under aerobic conditions. Moreover, the expected temperatures reached under continuous solar irradiation would be less than $40-50{ }^{\circ} \mathrm{C},{ }^{74}$ well below the degradation temperatures of the prepared materials ${ }^{42}$ and devices.

\section{Conclusions}

We have demonstrated that $Z n L$, a highly emissive red-emitting zinc (II) complex of the donoracceptor-donor (D-A-D) type ligand N,N'-bis(2-hydroxy-1-naphthylidene)-diaminomaleonitrile, once embedded into PMMA, confers to the resulting thin films optical efficiencies, which make them suitable for the preparation of LSCs. $Z n L$ displayed emission bands with maximum at $\lambda$ $>620 \mathrm{~nm}$ Stokes shift > $30 \mathrm{~nm}$, both in solutions and in PMMA, whose QY reached values of about $23 \%$. From the computational perspective, a discrete-continuum model approach was tested and validated to predict adsorption and emission properties of $Z n L$ in DOX and THF solutions by means of DFT and TD-DFT calculations. Despite the simplicity of our model, the results provided a reliable qualitative description of the structural features and transition energy trends in the different solvents. The same model applied to describe the $Z n L$ in PMMA film provided again results that have been confirmed by experiments. In light of these peculiar features, $Z n L /$ PMMA system yields $\mathrm{C}$ and $\eta_{\text {opt }}$ of maximum 0.92 and 6.92, respectively, which were found comparable to that gathered from LSC based on LR in the same range of fluorophore concentration and geometrical factor. These performances were attributed to the larger Stokes shift of $Z n L$ that prevents loss of efficiencies due to self-absorption and moves $Z n L$ emission more within the range of the highest quantum efficiency of the PV cell. Future approaches for $\eta_{\text {opt }}$ enhancement should adopt new synthetic strategies aimed at increasing the fluorophore QY while maintaining the emission maxima $>600 \mathrm{~nm}$. Considering the easy and economic preparation, all findings consistently support the effective use of the red-emitting zinc complex in the realization of cost-effective LSC.

\section{Acknowledgements}

The research leading to these results has received funding from MIUR-FIRB (RBFR122HFZ) and in part from the European Research Council under the European Union's Seventh Framework Programme (FP/2007-2013) / ERC Grant Agreement n. [320951]. ERGA TAPES Srl and BASF Italia S.p.A are kindly acknowledged for providing some free samples of "Microcellular ${ }^{\circledR}$ MCPET reflective sheet" and Lumogen Red F350, respectively. Dr. Marco Carlotti is kindly acknowledged for helpful discussions. 


\section{References}

1. M. Debije, Nature, 2015, 519, 298-299.

2. J. L. Sawin, Renewables Global Status Report, Renewable Energy Policy Network for the 21th Century, Paris, 2014.

3. W. G. J. H. M. van Sark, Renewable Energy, 2013, 49, 207-210.

4. W. T. Welford and R. Winston, Optics of nonimaging concentrators. Light and solar energy, 1978.

5. A. Rabl, Solar Energy, 1976, 18, 93-111.

6. A. Gombert, J. C. Miñano, P. Benitez and T. Hornung, in Photon Management in Solar Cells, Wiley-VCH Verlag GmbH \& Co. KGaA, 2015, DOI: 10.1002/9783527665662.ch6, pp. 153-182.

7. R. M. Swanson, Progress in Photovoltaics: Research and Applications, 2000, 8, 93-111.

8. G. Smestad, H. Ries, R. Winston and E. Yablonovitch, Solar Energy Materials, 1990, 21, 99-111.

9. G. A. Madhugiri and S. R. Karale, International Journal of Modern Engineering Research, 2012, 2, 1381-1385.

10. N. Tiwari and K. Mishra, Advanced Renewable Energy Sources, Royal Society of Chemistry, London, 2012.

11. J. C. Goldschmidt, L. Prönneke, A. Büchtemann, J. Gutmann, L. Steidl, M. Dyrba, M.-C. Wiegand, B. Ahrens, A. Wedel, S. Schweizer, B. Bläsi, R. Zentel and U. Rau, in Photon Management in Solar Cells, Wiley-VCH Verlag GmbH \& Co. KGaA, 2015, DOI: 10.1002/9783527665662.ch11, pp. 283-321.

12. S. T. Bailey, G. E. Lokey, M. S. Hanes, J. D. M. Shearer, J. B. McLafferty, G. T. Beaumont, T. T. Baseler, J. M. Layhue, D. R. Broussard, Y.-Z. Zhang and B. P. Wittmershaus, Solar Energy Materials and Solar Cells, 2007, 91, 67-75.

13. A. Sanguineti, M. Sassi, R. Turrisi, R. Ruffo, G. Vaccaro, F. Meinardi and L. Beverina, Chemical Communications, 2013, 49, 1618-1620.

14. M. G. Debije and P. P. C. Verbunt, Advanced Energy Materials, 2012, 2, 12-35.

15. M. Tonezzer, D. Gutierrez and D. Vincenzi, Solar Cell Nanotechnology, 2014, DOI: 10.1002/9781118845721.ch12, 293-315.

16. Y. S. Lim, S. Y. Kee and C. K. Lo, Solar Cell Nanotechnology, 2014, DOI: 10.1002/9781118845721.ch11, 271-291.

17. R. Turrisi, A. Sanguineti, M. Sassi, B. Savoie, A. Takai, G. E. Patriarca, M. M. Salamone, R. Ruffo, G. Vaccaro, F. Meinardi, T. J. Marks, A. Facchetti and L. Beverina, Journal of Materials Chemistry A: Materials for Energy and Sustainability, 2015, 3, 8045-8054.

18. F. Meinardi, A. Colombo, K. A. Velizhanin, R. Simonutti, M. Lorenzon, L. Beverina, R. Viswanatha, V. I. Klimov and S. Brovelli, Nature Photonics, 2014, 8, 392-399.

19. G. Griffini, M. Levi and S. Turri, Renewable Energy, 2015, 78, 288-294.

20. Y. Zhao, G. A. Meek, B. G. Levine and R. R. Lunt, Advanced Optical Materials, 2014, 2, 606-611.

21. W. E. Benjamin, D. R. Veit, M. J. Perkins, E. Bain, K. Scharnhorst, S. McDowall, D. L. Patrick and J. D. Gilbertson, Chemistry of Materials, 2014, 26, 1291-1293.

22. M. J. Currie, J. K. Mapel, T. D. Heidel, S. Goffri and M. A. Baldo, Science, 2008, 321, 226228.

23. S. F. Daorta, M. Liscidini, L. C. Andreani, P. Scudo and R. Fusco, presented in part at the 26th European Photovoltaic Solar Energy Conference and Exhibition, Hamburg, 2011.

24. L. Desmet, A. J. M. Ras, D. K. G. de Boer and M. G. Debije, Opt. Lett., 2012, 37, 30873089.

25. J. C. Goldschmidt, M. Peters, A. Bosch, H. Helmers, F. Dimroth, S. W. Glunz and G. Willeke, Solar Energy Materials and Solar Cells, 2009, 93, 176-182. 
26. L. H. Slooff, E. E. Bende, A. R. Burgers, T. Budel, M. Pravettoni, R. P. Kenny, E. D. Dunlop and A. Büchtemann, physica status solidi (RRL) - Rapid Research Letters, 2008, 2, 257-259.

27. A. Goetzberger and W. Greube, Appl. Phys., 1977, 14, 123-139.

28. S. Flores Daorta, A. Proto, R. Fusco, L. Claudio Andreani and M. Liscidini, Applied Physics Letters, 2014, 104, -.

29. S. M. El-Bashir, F. M. Barakat and M. S. AlSalhi, Renewable Energy, 2014, 63, 642-649.

30. I. Coropceanu and M. G. Bawendi, Nano Letters, 2014, 14, 4097-4101.

31. F. Purcell-Milton and Y. K. Gun'ko, Journal of Materials Chemistry, 2012, 22, 1668716697.

32. S. J. Gallagher, B. C. Rowan, J. Doran and B. Norton, Solar Energy, 2007, 81, 540-547.

33. P. Wang, Z. Hong, Z. Xie, S. Tong, O. Wong, C.-S. Lee, N. Wong, L. Hung and S. Lee, Chemical Communications, 2003, DOI: 10.1039/b303591c, 1664-1665.

34. F. d. r. Averseng, P. G. Lacroix, I. Malfant, N. P $\sqrt{ }(\mathrm{Criss} \sqrt{ }(\mathrm{C}$, C. Lepetit and K. Nakatani, Inorganic Chemistry, 2001, 40, 3797-3804.

35. S. Di Bella, N. Leonardi, G. Consiglio, S. Sortino and I. Fragalà, European Journal of Inorganic Chemistry, 2004, 2004, 4561-4565.

36. H. Zhu, J. Fan, B. Wang and X. Peng, Chemical Society Reviews, 2015, 44, 4337-4366.

37. S. Enthaler and X.-F. Wu, in Zinc Catalysis, Wiley-VCH Verlag GmbH \& Co. KGaA, 2015, DOI: 10.1002/9783527675944.ch1, pp. 1-4.

38. C. M. da Silva, D. L. da Silva, L. V. Modolo, R. B. Alves, M. A. de Resende, C. V. B. Martins and Â. de Fátima, Journal of Advanced Research, 2011, 2, 1-8.

39. W. Qin, S. Long, M. Panunzio and S. Biondi, Molecules, 2013, 18, 12264.

40. T. Dienel, C. Bauer, I. Dolamic and D. Bruehwiler, Solar Energy, 2010, 84, 1366-1369.

41. G. Griffini, L. Brambilla, M. Levi, M. Del Zoppo and S. Turri, Solar Energy Materials and Solar Cells, 2013, 111, 41-48.

42. V. Liuzzo, W. Oberhauser and A. Pucci, Inorganic Chemistry Communications, 2010, 13, 686-688.

43. M. Carlotti, A. Panniello, E. Fanizza and A. Pucci, Solar Energy, 2015, 119, 452-460.

44. P. Hohenberg and W. Kohn, Phys. Rev., 1964, 136, 864-871.

45. W. Kohn and L. J. Sham, Phys. Rev., 1965, 140, A1133-A1138.

46. W. Kohn, A. D. Becke and R. G. Parr, The Journal of Physical Chemistry, 1996, 100, 12974-12980.

47. R. E. Stratmann, G. E. Scuseria and M. J. Frisch, J. Chem. Phys., 1998, 109, 8218.

48. C. T. Lee, W. T. Yang and R. G. Parr, Phys. Rev. B, 1988, 37, 785-789.

49. A. D. Becke, J. Chem. Phys., 1993, 98, 5648-5652.

50. A. D. McLean and G. S. Chandler, J. Chem. Phys., 1980, 72, 5639.

51. R. Krishnan, J. S. Binkley, R. Seeger and J. A. Pople, J. Chem. Phys., 1980, 72, 650.

52. P. J. Hay and W. R. Wadt, J. Chem. Phys., 1985, 82, 270.

53. L. E. Roy, P. J. Hay and R. L. Martin, J. Chem. Theory Comput., 2008, 4, 1029-1031.

54. S. Miertuš, E. Scrocco and J. Tomasi, Chem. Phys., 1981, 55, 117-129.

55. J. Tomasi, R. Cammi, B. Mennucci, C. Cappelli and S. Corni, Phys. Chem. Chem. Phys., 2002, 4, 5697-5712.

56. J. Tomasi, B. Mennucci and R. Cammi, Chemical reviews, 2005, 105, 2999-3093.

57. R. Improta, V. Barone, G. Scalmani and M. J. Frisch, J. Chem. Phys., 2006, 125, 054103.

58. R. Improta, G. Scalmani, M. J. Frisch and V. Barone, J. Chem. Phys., 2007, 127, 074504.

59. M. J. Frisch, G. W. Trucks, H. B. Schlegel, G. E. Scuseria, M. A. Robb, J. R. Cheeseman, G. Scalmani, V. Barone, B. Mennucci, G. A. Petersson, H. Nakatsuji, M. Caricato, X. Li, H. P. Hratchian, A. F. Izmaylov, J. Bloino, G. Zheng, J. L. Sonnenberg, M. Hada, M. Ehara, K. Toyota, R. Fukuda, J. Hasegawa, M. Ishida, T. Nakajima, Y. Honda, O. Kitao, H. Nakai, T. Vreven, J. A. Montgomery Jr., J. E. Peralta, F. Ogliaro, M. J. Bearpark, J. J. Heyd, E. N. 
Brothers, K. N. Kudin, V. N. Staroverov, R. Kobayashi, J. Normand, K. Raghavachari, A. P. Rendell, J. C. Burant, S. S. Iyengar, J. Tomasi, M. Cossi, N. Rega, N. J. Millam, M. Klene, J. E. Knox, J. B. Cross, V. Bakken, C. Adamo, J. Jaramillo, R. Gomperts, R. E. Stratmann, O. Yazyev, A. J. Austin, R. Cammi, C. Pomelli, J. W. Ochterski, R. L. Martin, K. Morokuma, V. G. Zakrzewski, G. A. Voth, P. Salvador, J. J. Dannenberg, S. Dapprich, A. D. Daniels, Ö. Farkas, J. B. Foresman, J. V. Ortiz, J. Cioslowski and D. J. Fox, Journal, 2009.

60. P. G. Lacroix, S. Di Bella and I. Ledoux, Chemistry of Materials, 1996, 8, 541-545.

61. G. Consiglio, S. Failla, I. P. Oliveri, R. Purrello and S. Di Bella, Dalton Transactions, 2009, DOI: 10.1039/b914930a, 10426-10428.

62. R. Improta and V. Barone, Chemical reviews, 2004, 104, 1231-1254.

63. F. Aquilante, V. Barone and B. O. Roos, J. Chem. Phys., 2003, 119, 12323.

64. S. Chakraborty, C. R. Bhattacharjee, P. Mondal, S. K. Prasad and D. S. S. Rao, Dalton Transactions, 2015, 44, 7477-7488.

65. T. L. Richardson and E. Lokensgard, Industrial Plastics: Theory and Applications, Delmar Publishers Inc., Albany, NY, 1997.

66. L. H. Sperling, Introduction to Physical Polymer Science, John Wiley \& Sons, Inc., Hoboken, New Jersey, 4th edn., 2006.

67. B. Valeur and M. N. Berberan-Santos, Molecular Fluorescence: Principles and Applications, Wiley-VCH, Weinheim (Germany), second edn., 2013.

68. O. M. ten Kate, K. W. Kraemer and E. van der Kolk, Solar Energy Materials \& Solar Cells, 2015, 140, 115-120.

69. S. F. H. Correia, P. P. Lima, P. S. Andre, M. R. S. Ferreira and L. A. D. Carlos, Solar Energy Materials \& Solar Cells, 2015, 138, 51-57.

70. A. L. Rodarte, F. Cisneros, L. S. Hirst and S. Ghosh, Liquid Crystals, 2014, 41, 1442-1447.

71. B. Balaban, S. Doshay, M. Osborn, Y. Rodriguez and S. A. Carter, Journal of Luminescence, 2014, 146, 256-262.

72. C. Tummeltshammer, A. Taylor, A. J. Kenyon and I. Papakonstantinou, Solar Energy Materials and Solar Cells, 2016, 144, 40-47.

73. M. Carlotti, G. Ruggeri, F. Bellina and A. Pucci, Journal of Luminescence, 2016, 171, $215-$ 220.

74. V. A. Rajkumar, C. Weijers and M. G. Debije, Renewable Energy, 2015, 80, 308-315. 


\section{Graphical abstract}

Red light and concentrated: a Zinc complex embedded in PMMA yields a cost-effective and efficient luminescent solar concentrator

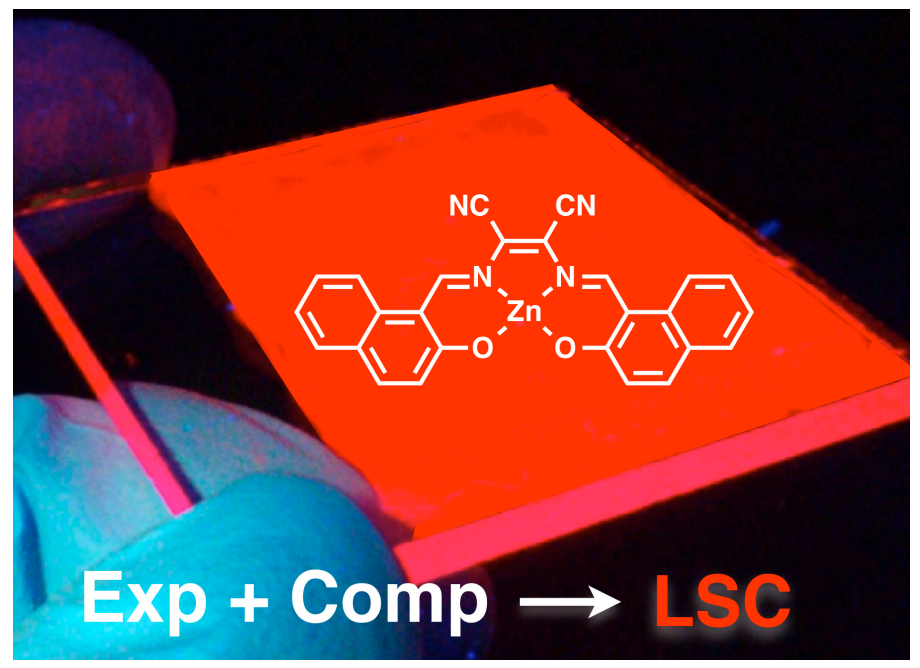

